\title{
Tetralogy of Fallot in teenagers and adults: surgical experience and follow-up
}

\author{
Akshay Kumar Bisoi, MCh \\ John Santosh Kumar Murala, MCh \\ Balram Airan, MCh · Ujjwal Kumar Chowdhury, MCh \\ Shyam Sunder Kothari, DM • Hemraj Pal, MD \\ Chetan D. Patel, MD - Cheemalapati Sai Krishna, MCh \\ Sandeep Chauhan, MD · Venugopal Panangipalli, MCh
}

(C) The Japanese Association for Thoracic Surgery 2008

\section{Erratum to: Gen Thorac Cardiovasc Surg (2007) 55:105-112 \\ DOI 10.1007/s11748-006-0087-1}

The correct name of the eighth author should be given as Cheemalapati Sai Krishna, not Sai Krishna Cheemalapati.

Accordingly, the correct name in the affiliation list should be C. Sai Krishna.

This online version of the original article can be found at http://dx.doi.org/10.1007/s11748-006-0087-1.

A.K. Bisoi $(\varangle) \cdot$ J.S.K. Murala · B. Airan · U.K. Chowdhury · C. Sai Krishna $\cdot$ V. Panangipalli

Department of Cardiothoracic and Vascular Surgery, All India Institute of Medical Sciences, Ansari Nagar, New Delhi 110029, India

Tel. +91-11-2658-8246/2658-8500 (ext. 4844);

Fax +91-11-26862663

e-mail: bisoiak@rediffmail.com

\section{S.S. Kothari}

Department of Pediatric Cardiology, All India Institute of Medical Sciences, Ansari Nagar, New Delhi 110029, India

H. Pal

Department of Psychiatry, All India Institute of Medical

Sciences, Ansari Nagar, New Delhi 110029, India

C.D. Patel

Department of Cardiac Nuclear Medicine, All India Institute of Medical Sciences, Ansari Nagar, New Delhi 110029, India

S. Chauhan

Department of Cardiac Anesthesia, All India Institute of Medical Sciences, Ansari Nagar, New Delhi 110029, India 